\title{
UAV PHOTOGRAMMETRY IMPLEMENTATION TO ENHANCE LAND SURVEYING, COMPARISONS AND POSSIBILITIES
}

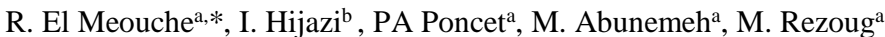 \\ ${ }^{a}$ Université Paris-Est, Institut de Recherche en Constructibilité, ESTP-Paris, F-94230, Cachan, France \\ ${ }^{\mathrm{b}}$ An-Najah National University, Nablus, Palestine \\ *relmeouche@estp-paris.eu
}

\section{Commission VI, WG VI/4}

KEY WORDS: Land Surveying, UAV, Photogrammetry, Point Cloud, 3D Model.

\begin{abstract}
:
The use of Unmanned Aerial Vehicles (UAVs) for surveying is now widespread and operational for several applications - quarry monitoring, archeological site surveys, forest management and 3D modeling for buildings, for instance. UAV is increasingly used by land surveyors especially for those kinds of projects. It is still ambiguous whether UAV can be applicable for smaller sites and property division. Therefore, the objective of this research is to extract a vectorized plan utilizing a UAV for a small site and investigate the possibility of an official land surveyor exploiting and certificating it. To do that, two plans were created, one using a UAV and another utilizing classical land surveyor instruments (Total Station). A comparison was conducted between the two plans to evaluate the accuracy of the UAV technique compared to the classical one. Moreover, other parameters were also considered such as execution time and the surface covered. The main problems associated with using a UAV are the level of precision and the visualization of the whole area. The results indicated that the precision is quite satisfactory with a maximum error of $1.0 \mathrm{~cm}$ on ground control points, and $4 \mathrm{~cm}$ for the rest of the model. On the other hand, the results showed that it is not possible to represent the whole area of interest utilizing a UAV, due to vegetation.
\end{abstract}

\section{INTRODUCTION}

Land surveying is one of the oldest professions on earth. The purpose of many surveys nowadays is to create a $2 \mathrm{D}$ plan that a land surveyor and his client could use to obtain a building permit. Innovation in topography and land surveying is aimed at acquiring more data with higher accuracy. Computer developments were a key change in that regard. Nowadays, utilizing drones could lead to another quantum leap in the surveying profession. With the development of smart cities and BIM technologies, it will probably become easy to create a 3D model of a terrain utilizing UAVs and exporting it to a 3D Geographic Information System (GIS). Up until now, for construction sites, 2D plans have been required to get reliable measurements quickly.

Topographic plans are widely used in a variety of applications and at various sites. These plans involve several levels of accuracy depending on the client's needs. Usually, projects that require crucial safety conditioning for construction, such as high-speed railways, landing strips, investigating building deformations or tunnel inspections, require plans with high accuracy, where just a few millimeters $(\mathrm{mm})$ of deformation are highly significant. In some countries land surveyors' signature has a legal value. Their tasks involve ensuring the accuracy of a plan and making sure that the landmarks are assigned to the right place. Actually, they use topographic instruments in order to realize the plans. This involves a broad number of applications from private properties to major public infrastructures, roads and network management, for instance.

For many topographical surveys, the data are acquired with a total station. A total station is surveying equipment that consists of an electromagnetic measuring instrument and electronic theodolite. It is also integrated with a microprocessor, electronic data collector and storage system. The instrument can be used to measure horizontal and vertical angles as well as the slope distance from the object to the instrument. The redundant measures with total stations allow accuracy to within millimeters to be achieved. Furthermore, their automatic operation enables more data to be acquired in a limited period of time. Over one day a land surveyor can acquire up to 2,000 points. Since the process is repetitive it can easily involve errors.

Therefore several techniques can be adopted to avoid, or at least minimize, these possible errors. For instance, the French government set specific legislation on precision classes for topographical surveys in order to control the quality of the data. The Arrêté du 16 septembre 2003 establishes a set of equations and values to confirm that topographical surveys comply with a designed class of precision.

The survey then has to be georeferenced using different techniques based on the nature of the terrain and the available instruments. Usually, the most efficient technique used is a global navigation satellite system (GNSS) receiver with a real-time kinematic (RTK) network. This allows control points to be obtained with a precision of about 2.0 $\mathrm{cm}$.

Once the field survey is completed, the data are transferred to $\mathrm{CAD}$ software to generate the plan. Even though codification in the field enables automatic drawing, it usually involves some errors, and the post-treatment process usually takes several hours to obtain the final product.

In France, the land property is registered in a document called a "cadastre" (land register). This was first established in the 19th century in the reign of Napoleon. The evolution of topographic instruments and progress in terms of precision revealed that most of the register was inaccurate. Therefore,

\footnotetext{
* Corresponding author
}

* Corresponding author 
an operation called "bornage" was established to set property boundaries. The goal is to implant the landmarks to set a property's limits. During a "bornage," land surveyors work as a legal expert to delimitate the boundaries between neighbors. The "bornage" encompasses several operations: (1) creation of a "plan de bornage" (this comprises a topographical plan of the state of the property and the projected boundaries); (2) the acceptance of the plan by the mayor and neighbors; (3) the projection of the boundaries and generation of a topographical plan of the property after the projection. Various studies have been conducted on using UAV images and photogrammetry for cadastral surveys (Kurczynski, 2016) over large areas and with a precision of 5-10 cm. Kim et al. 2014 examined the effectively of UAV for land monitoring in order to analyze and detect disaster areas. They evaluated the accuracy of the digital maps generated from UAV images. They found that the mean error, if only GPS/INS data used, is about $10 \mathrm{~m}$, whereas if ground control point (GCP) used, the mean error is about $10 \mathrm{~cm}$.

Jin et al. 2009 reviewed a theoretical development of UAV in several implementations fields. They recapped the common problems associated with UAV remote sensing. They also provided information on the orientations of future research about it. Rui-sheng et al. 2006 suggested a new methodology of utilizing UAV images to enhance government decision making related to the land use survey. They found that the implementation of UAV image in land use survey is viable, low-cost and promising. Jones IV et al. 2006 proposed characteristics of small UAV to be suitable for management and research tools. They used wingspan UAV to investigate its usefulness for wildlife research applications. Brutto et al. 2014 performed a study on cultural heritage area utilizing different UAV systems. Two different datasets were acquired one for archeological site and another for land art site. They developed 3D model and ortho-images with high level of details. In addition, they conducted some tests to investigate the accuracy of images orientation and 3D models.

Tscharf et al. 2015 presented an automated processing pipeline utilizing various images platforms. The developed framework allows for geo-referencing of UAV imagery based on GPS measurements and ground control points (GCPs). The framework also allows for developing enrich 3D models. Grenzdörffer et al. 2008 indicated that the micro UAVs with light weight are much flexible and weather independent compared to standard ones. They are useful for forestry and agricultural applications. They stated that the current potential photogrammetry for direct georeferencing has not fully exploited. This can be attributed to the manufacturers of UAVs whom are not aware and familiar with the spatial needs of photogrammetry and GIS data acquirement.

The aim of this study is to evaluate the potential of UAVs for much smaller areas and with the best precision possible.

\section{UNMANNED AERIAL VEHICLE (UAV)}

According to (Colomina and Molina, 2014), UAV photogrammetry has witnessed rapid development in the past few years. This can be attributed to the accessibility of drones and a major development of Structure from Motion software. Before UAVs, aerial photogrammetry involved planes or helicopters and metric cameras. It encompassed complex and various processes due to the heights to which the aircraft soared and the expensive cost of metric cameras and flight hours. It now offers an affordable access to precise aerial mapping (Fraser, 2015).

According to (Küng, 2011), the developments of UAVs in recent years along with the improvements in Structure from Motion (SFM) software and computer vision enhanced the production of photogrammetry. They made it accessible with centimetrical precision even with bad positioning systems onboard the aircraft. This precision is approximately within the same range as the existing technologies for most land surveying purposes. Application requiring millimetric precision is still out of the range of possibilities for UAVs. UAVs are becoming more and more affordable, and the ultralight and user-grade cameras on-board also offer very good resolution for low-altitude photogrammetric work. Moreover, UAVs are becoming easier to use with automated flight planners and automatic obstacle detection. The most common applications and operations associated with UAVs are: stockpile measurements and quarry monitoring, precision agriculture, infrastructure inspection, forest management, coastal erosion studies and other environmental and archeological projects (Fernandez and Gutierrez, 2016), (Goncalves and Henriques, 2015) and (Stöcker, 2015). UAVs are extremely efficient for these applications, particularly for quarries, since they actually provide high precision with less time and safe conditions (Arango and Morales, 2015). Indeed, Arango and Morales 2015 compared UAV volumetric measurements with those from TST. The results obtained from UAV presented $0.67 \%$ difference with the volume determined by weighting, whereas, TST presented $2.88 \%$. This research is related to vectorizing polylines and polygons. The utilization of UAVs by land surveyors is growing nowadays. They mostly use it for large open sites and for volumetric measurements (Gonzales-Aguilera, 2012). Therefore one of the most significant questions that is raised is related to the suitability and capability of UAVs for all sites, and whether utilizing UAVs will dispense of the traditional surveying techniques.

Thus, the main goals of this research are to evaluate the operational capabilities of UAVs on small sites, and to evaluate the potential of UAV-assisted photogrammetry in creating a topographical plan of land property. To achieve these objectives, a collaboration was undertaken with a land surveying office. The study was conducted on one of their sites. The land surveyor office developed and generated a plan using traditional topographic instruments, whereas we used UAV-assisted photogrammetry. After that, a comparison between the two surveying approaches was conducted.

\section{INSTRUMENTS AND SOFTWARES}

\subsection{Total station}

A total station is an electronic/optical instrument widely used for surveying. It consists of an electronic theodolite and electronic distance meter (EDM). It is integrated with a microprocessor, electronic data collector and storage system. The instrument can be used to measure horizontal and vertical angles as well as the slope distance from the object to the instrument (Kavanagh and Bird, 1996). In this study, a Trimble M3 was used. The technical characteristics of the Trimble M3 are:

Distances:

Accuracy (standard deviation based on ISO 17123-4)

Prism: $\pm(2+2 \mathrm{ppm} \times \mathrm{D}) \mathrm{mm}$

Reflectorless: $\pm(3+2$ ppm x D) $\mathrm{mm}$

Angles:

DIN 18723 accuracy (horizontal and vertical):

1", 2"/0.5 mgon, 3"/1.0 mgon, 5"/1.5 mgon 


\subsection{UAVs}

In this study, two different UAVs (Ebee and HDS3) were utilized to perform two different tests on the same site. The Ebee was used in the first test. It is a flying wing that weighs $700 \mathrm{gm}$. It can fly at up to $80 \mathrm{~km} / \mathrm{h}$ and carry a compact camera up to 18 Mpix as shown in Figure 1a. It is associated with a very user-friendly steering interface that can be installed on a computer. The flight plan is set in advance to determine the flight height required for a given ground resolution. It can fly for up to 40 minutes within a range of $3.0 \mathrm{~km}$ from the base station. It can cover an area of around 45 ha during a 25-minute flight. But it is highly dependent on the height of flight, resolution and overlap.

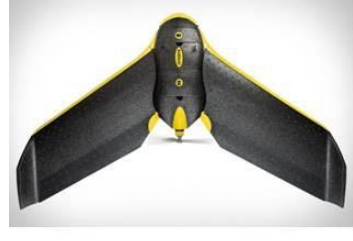

a

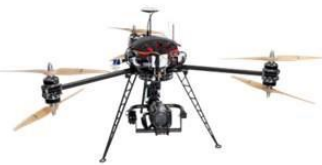

b
Figure 1: UAVs utilized in the study: (a) Ebee, (b) HDS3.

The HDS3 is another UAV and was used in the second test; it is shown in Figure 1b. It is a hexacopter using a DJI flying controller. A multicopter flies very differently from a flying wing. It can perform stationary flights and soar at very low heights. The HDS3 weighs $2.0 \mathrm{~kg}$ and can fly at up to $70 \mathrm{~km} / \mathrm{h}$; it was equipped with a Panasonic GH4 with Olympus lens for a total weight of less than $4.0 \mathrm{~kg}$. The HDS3 was piloted manually, since the DJI ground control automated piloting system had not been adapted to comply with this research's requirements.

\subsection{Cameras}

The cameras that were utilized with each UAV were a Canon S110 for the Ebee and Panasonic GH4 for the HDS3. Their properties are displayed in Table 1.

\begin{tabular}{|c|c|c|}
\hline & Canon S110 & $\begin{array}{c}\text { Panasonic GH4 } \\
\text { (with Olympus) }\end{array}$ \\
\hline Type of sensor & CMOS & Live MOS Sensor \\
\hline $\begin{array}{c}\text { Effective number of } \\
\text { pixels }\end{array}$ & $\begin{array}{c}\text { About } 12.1 \\
\text { megapixels }\end{array}$ & 16.05 megapixels \\
\hline Focal length & $\begin{array}{c}5.2 \text { to } 26 \mathrm{~mm}(\text { equivalent } \\
24 \times 36: 24 \text { to } 120 \mathrm{~mm})\end{array}$ & $12 \mathrm{~mm}$ \\
\hline Maximal opening & $\mathrm{f} / 5.9$ & $\mathrm{f} / 2$ \\
\hline ISO sensitivity & $80-12,800$ & $100-25,600$ \\
\hline Shutter speed & $15-1 / 2000 \mathrm{~s}$ & $60 \mathrm{~min}-1 / 16,000 \mathrm{~s}$ \\
\hline GPS recording & Yes & No \\
\hline Weight & $198 \mathrm{gm}$ & $690 \mathrm{gm}$ \\
\hline
\end{tabular}

Table 1: Cameras' properties

\subsection{Cameras Software}

Different software was used to obtain the final results:

1. Photoscan is photogrammetry software used to create and export various data; point clouds, orthophotos, 3D models, digital elevation models, for instance. It is based on powerful image matching and autocorrelation algorithms to create a point cloud. The matching and registration are done automatically with this software. It also includes meta-data about the camera's position ( $\mathrm{x}, \mathrm{y}$, $\mathrm{z}$ ) in the reference system's coordinates and the roll tilt and yaw of the camera for every picture. It allows the model to be referenced to ground control points. Figure 2 displays the process conducted within Photoscan. In all of these steps, it is possible to set parameters that will influence the process and the quality of the model. Moreover, a Python interface can be used to establish an automated process. A set of images are uploaded enabling the Python interface to generate the results at the press of a button.

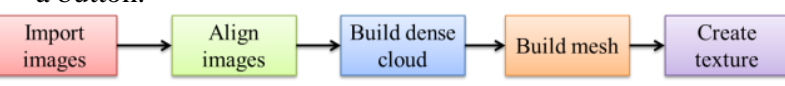

Figure 2: Photoscan process.

2. Pix4D is very similar to Photoscan, but it is already automated and the parameter must be set before starting the process. It also provides a tool for vectorizing the model within Pix4D.

3. ArcGIS is the most widely used GIS. It has great capabilities in terms of $3 \mathrm{D}$ analysis with the extension $3 \mathrm{D}$ analyst. It also includes Arcscene, which enables efficient work on heavy point clouds and 3D models.

4. AutoCAD is CAD software, which is used by most land surveyors and in many other professions. It is efficient for generating $2 \mathrm{D}$ topographic plans, but it is not optimized to deal with heavy 3D data exploitation.

\section{GENERATION OF POINT CLOUDS, 3D MODELS AND ORTHOPHOTOS}

The study was conducted over a private terrain in Etampes. Etampes is located to the south of Paris at the border of the Paris suburbs and presents a medium urban density. The whole field survey utilizing a UAV took approximately four hours. On the other hand, the field operation performed by the land surveying office utilizing a total station took about a full working day for the same site.

\subsection{Preparation}

Flying in semi-urban areas, similar to the one that was surveyed in this study, requires serious preparation and understanding of aerial maps in order to obtain the legal permit and authorization to start flying over the area.

France is one of the first countries in the world to set legislation rules for UAV flights. These rules are synthesized in four flight scenarios as shown in Figure 3.
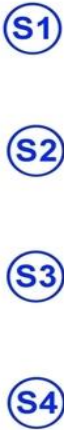

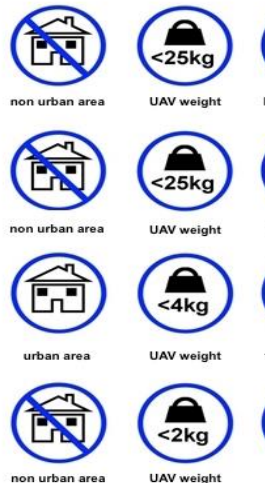

Don urban area

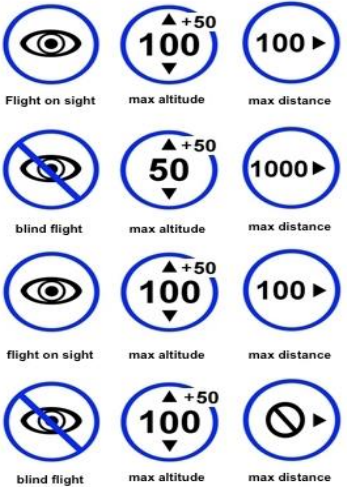

(
Figure 3: UAV flight rules utilized in France. 
The first test was conducted considering scenario 2 (S2) utilizing an Ebee drone. The capabilities offered by the camera and the legal limits of this scenario did not provide precise work. Indeed the topography of the area and the height of the trees and buildings necessitated flying at a height of $70 \mathrm{~m}$ over the zone of interest. Thus, with scenario 2 (S2), only 10 images were generated for the model with a $5 \mathrm{~cm}$ GSD, which was not relevant for this study.

The second test was conducted over the same site using a different flight scenario (S3) and a different UAV. A multirotor drone equipped with a DSLR camera was utilized to provide better data quality. Actually, scenario 3 (S3) required authorization from the mayor's office and of course from the proprietor of the terrain. Obtaining authorization from the mayor's office takes up to three weeks, so this is a real issue and it is considered one of the shortcomings of utilizing UAVs.

\subsection{Image acquisition process}

The image acquisition process is probably the most complex part of field operations. It involves a lot of parameters that have a major influence on the results. Moreover, it is not easy to come back and acquire new data due to logistical problems such as flight authorization and weather.

To obtain the best images, the camera should be calibrated by setting its parameters on the ground. The best images for photogrammetry are the sharpest and with a maximum of texture. Usually it is required to set the ISO before the flight and leave the shutter speed and diaphragm opening to function automatically.

To examine and evaluate camera calibration one has to take a picture of the site, including many bright and dark zones, while moving. Once you have obtained a picture that is sharp and has no burnt or underexposed area, the camera can be loaded onto the drone.

There are several factors influencing a flight plan, including the desired resolution, the area to be covered and the height variations over the terrain. The expected resolution has a direct impact on the height of flight. The area to be covered determines the number of flight lines. Moreover, the variation of height of flight influences the overlapping values between images.

The resolution, pixel size or GSD is the size of the projected pixel on the ground. It is directly dependent on the sensor's size and height of flight. As far the terrain is not entirely flat, thus this value is an average of the different pixel size in the model. For instance, a GSD of $1.0 \mathrm{~cm}$ means that the pixels on the image represent $1.0 \times 1.0 \mathrm{~cm}$ on the ground. The resolution will dictate what is possible to achieve. Indeed it dictates the accuracy which is possible to vectorise objects on an ortho-photo, thus defining the possibilities for realization of engineering and infrastructure projects (Kulur 2016). In this study the vectorization was realized on the point cloud. If it is not possible to fly automatically, someone with experience can manually take the pictures indicating the trajectory to the pilot. Nowadays, post-processing software is powerful and efficient enough to work with a set of pictures that is not completely perfect. In this study the flight was performed manually due to weather conditions and a lack of reliability on the automatic flight software available for the drone. The pilot was in charge of the drone trajectory, while another operator was in charge of taking the pictures and giving instructions to the pilot. The operator indicated to the pilot the trajectory that he should follow and shuttered the pictures at the same time. On usual photogrammetric missions the drone has an automatic flight planner and the pilot is only there to ensure the mission goes well. Whatever the case, an ideal flight plan should be set and must be followed as precisely as the conditions allow. Here, due to the weather conditions, it was difficult to work at very low altitude with trees and buildings really close to the drone. The whole process, including preparation, controlling and saving the data and the flight time, took approximately four hours.

Figure $4 \mathrm{a}$ presents the camera position and number of overlapping images on the terrain. It is possible to identify the flight lines that were executed. At the end, the global set of pictures presents a good level of overlapping and is of good quality.

Two problems should be noted: first, the existence of an overlapping problem. This can be seen from the gradation of color within the image (from red corresponding to 1 picture overlap to blue corresponding to 9 picture overlaps over the same area). There is a hole in the overlapping map as shown in Figure 4. It corresponds to a gable (Figure 4b) that was the highest part of the house, inducing a lack of overlapping as the drone was too close to it. The second problem is related to the borders of the terrain that lack a bit of overlapping. To solve the overlapping problem on the borders one has to cover an area wider than the one of interest, but in this case it was difficult as the border of the terrain was also the limit of the area where the UAV was allowed to fly.

Therefore, this made some slightly weak overlapping values over some borders. Fig. 5 presents the overlapping problems due to the existence of terrain that was not flat.
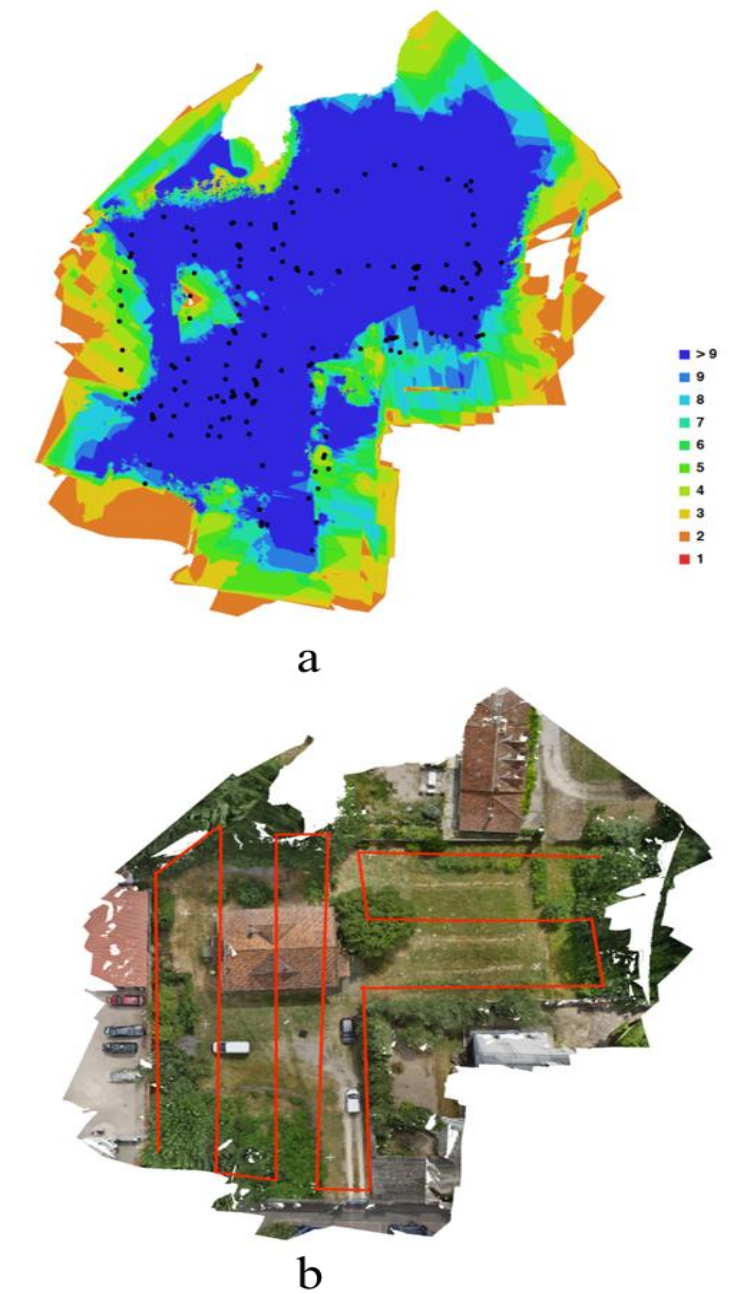

Figure 4: (a) image overlapping level; (b) orthophoto. 


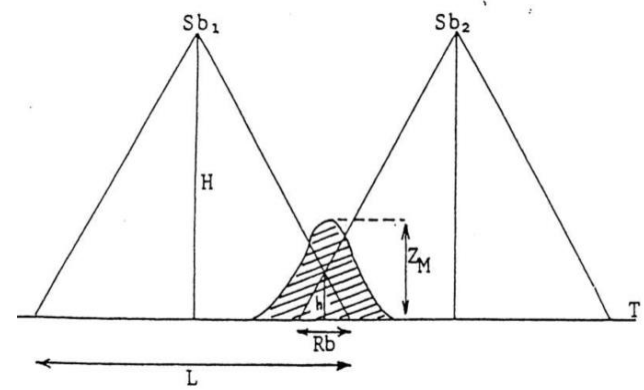

Figure 5: Overlapping problem over non flat terrain.

\subsection{Ground control points acquisition process}

To obtain the best resolution possible it is necessary to use ground control points. Previous works (Eling, 2015) show that on-board georeferencing allows a $5 \mathrm{~cm}$ precision at best. This study seeks a better precision with low heights of flight and ground control points.

For the references, five crosses were placed as displayed in Figure 6 utilizing a 100*100 $\mathrm{cm}$ white plastic cross template. They were placed as homogeneously as possible (Figure 6) on the site in order to obtain the best referencing on the whole model. Then a closed traverse with the total station was realized using the center of each cross as the summit of the polygon. A closed traverse is a traverse that begins and ends at the same point or that begins and ends at points whose position has been previously determined. In both cases the angles can be closed geometrically and the position closure can be determined mathematically.
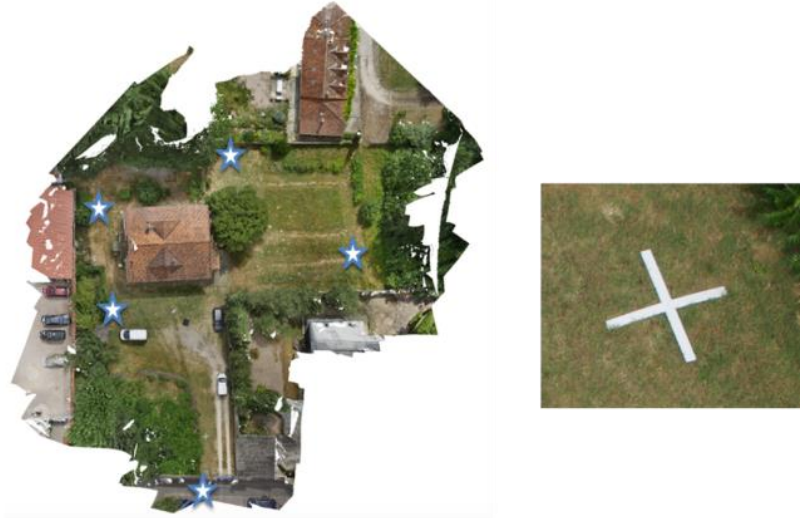

Figure 6: Reference points position.

\subsection{Photoscan/Pix4D software}

A total of 181 images were downloaded on the software after sorting out the useless ones (blurred, out of the area). The first image matching is processed with low quality in order to conduct the georeferencing process, where markers have to be positioned at each reference point. The file is then imported with the coordinates of every reference. The georeferencing level of precision for drone-acquired data or traditional instruments does not change, because the methods used to georeference it are the same: GNSS receiver or traverse to a known reference. This is the reason why local polygonal coordinates were used in order to create the model based on five reference points. Once the markers are placed and the coordinates assigned, a second image matching is processed based on the coordinates, to generate dense cloud points with references.

This point is essential in this study; the objective is not to evaluate the precision of the absolute coordinates of the model but the relative coordinates. That's why a closed traverse was conducted in order to obtain the most precise set of references in local (arbitrary) coordinates.

It is also essential to understand that the crosses, that were placed as base stations for the traverse are used to set the scale and orientation of the model. The same thing can be performed by measuring remarkable objects and inserting these values into the software, and indicating vertical orientation with the ridge of a building. However, the process involving a total station and ground reference provides better precision due to longer distance and controls on the measures. The final results generated are: a point cloud, a 3D model, an orthophoto and a digital elevation model. The most significant result for this study is the point cloud, where vectorization can be executed with better accuracy. The reason behind processing the project in Pix 4D mapper was to be able to vectorize directly on the points cloud. Tables 2 and 3 display the error produced by Photoscan on ground control points. They show a mean error of $7.0 \mathrm{~mm}$ for the reference points and $4.0 \mathrm{~cm}$ for control points.

\begin{tabular}{|l|l|l|l|l|l|l|}
\hline Label & $\mathrm{X}$ error $(\mathrm{m})$ & $\mathrm{Y}$ error $(\mathrm{m})$ & $\mathrm{Z}$ error $(\mathrm{m})$ & Error $(\mathrm{m})$ & Projections & Error $(\mathrm{pix})$ \\
\hline point 1 & -0.000200 & -0.005034 & 0.004149 & 0.006527 & 12 & 0.274085 \\
\hline point 2 & -0.006103 & 0.004499 & -0.006211 & 0.009801 & 13 & 0.976952 \\
\hline point 3 3 & 0.005066 & -0.002100 & 0.002247 & 0.005927 & 8 & 0.373336 \\
\hline point 4 & 0.001990 & -0.005024 & 0.002603 & 0.005998 & 33 & 0.283722 \\
\hline point 5 5 & -0.000744 & 0.007662 & -0.002780 & 0.008184 & 13 & 0.525679 \\
\hline Avg. & 0.003673 & 0.005176 & 0.003882 & 0.007440 & 79 & 0.511550 \\
\hline
\end{tabular}

Table 2: Error for the reference points

\begin{tabular}{|l|l|l|l|l|l|l|}
\hline Label & X error $(\mathrm{m})$ & Y error $(\mathrm{m})$ & Z error $(\mathrm{m})$ & Error $(\mathrm{m})$ & Projections & Error (pix) \\
\hline point 6 & -0.015552 & -0.005212 & 0.036690 & 0.040189 & 29 & 0.212501 \\
\hline
\end{tabular}

Table 3: Error for the control point

\section{DATA CONTROLS AND EXPLOITATION}

\subsection{Model georeferencing with ArcGIS}

Once the model had been created, an ArcGIS georeferencing tool was used to manually check the accuracy of the orthophoto and have another control on precision. Indeed georeferencing in Photoscan implied manually pointing the reference and this other tool allowed us to point the reference on the orthophotos making for another test of accuracy. The process starts through exporting the orthophoto from Photoscan and the coordinates of the ground control points. The main problem encountered in georeferencing was attributed to assigning the position of the reference on the image. Therefore the references were set at the center of the white crosses as shown in Figure 7.

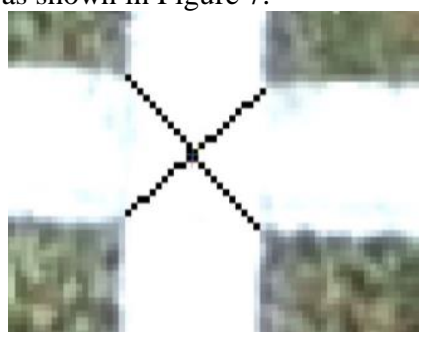

Figure 7: Drawn crosses.

The results shown in Fig. 8 confirm that the model respects the precision of a total station measurement by mapping the points on a picture. Moreover, the control points reach a residual error of $9.0 \mathrm{~mm}$, which is acceptable for a topographic plan. 


\begin{tabular}{|c|c|c|c|c|c|c|c|}
\hline \multicolumn{2}{|c|}{$+e^{+}+x^{+}+t^{+}$} & \multicolumn{2}{|c|}{ Total RMS Error: } & \multicolumn{4}{|c|}{ Forward:0,00589013 } \\
\hline Link & X Source & Y Source & Х Мар & Y Map & Residual_x & Residual_y & Residual \\
\hline 1 & 984,150133 & 5021,579359 & 984,153023 & 5021,579595 & $-0,000479411$ & $-0,00397266$ & 0,00400148 \\
\hline 2 & 981,587810 & 5039,579229 & 981,583390 & 5039,580061 & $-0,00284116$ & $-0,00318113$ & 0,00426518 \\
\hline 3 & 994,427535 & 5021,891943 & 994,440500 & 5021,897900 & 0,00889029 & 0,00401487 & 0,00975482 \\
\hline 4 & 1005,107078 & 5049,104762 & 1005,103403 & 5049,108792 & $-0,00138342$ & 0,00557464 & 0,00574374 \\
\hline 5 & 999,993778 & 4999,995946 & 1000,000000 & 5000,000000 & $-0,00405983$ & 0,00241162 & 0,00472209 \\
\hline 6 & 1026,327804 & 5030,942881 & 1026,331807 & 5030,932600 & $-0,000126473$ & $-0,00484735$ & 0,004849 \\
\hline
\end{tabular}

Figure 8: Georeferencing results from ArcGIS.

\subsection{Vectorization in AutoCAD/Pix4D}

One of the objectives of this research is to know whether the acquired results can be used to create an entire topographic plan or not. So the plan was vectorized on Pix4D by mapping between the points cloud and the points that were obtained from the field utilizing a total station. The main problem for that is the existence of vegetation. It covers large areas of the site including boundaries, which makes it impossible to vectorize those areas. Thus, only the most relevant and visible points, such as roofs, houses, walls and pillar angles, were vectorized.

But even on the most relevant points some errors can be induced. Indeed the points are determined manually and the model can present some small artifacts resulting in potential errors.
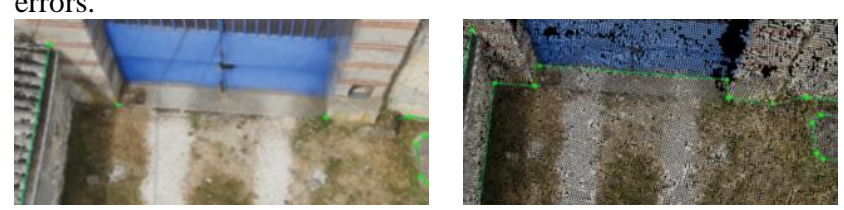

Figure 9: Illustration of potential manual pointing errors.

This may lead to some potential centimeter errors. In order to minimize the pointing errors, the distance between our identified points and the land surveyor's points was measured in three different timings of the UAV plan: twice using different reference points, and the third time also modifying the scale of our plan. Another source of error is the 3D similitude in transferring the UAV plan, which is in local coordinates, to the land surveyor's plan, which is in Lambert 93.

Two different averages were calculated: one for the points on the ground, and the other one for the roof points (which were measured with a laser pointer). The results of the average distance between the land surveyor points and the 3D model points are presented in Table 4.

\begin{tabular}{|c|c|c|c|}
\hline & No. 1 & No. 2 & Rescaling \\
\hline $\begin{array}{c}\text { Ground } \\
\text { Points }\end{array}$ & $3.79 \mathrm{~cm}$ & $4.35 \mathrm{~cm}$ & $3.35 \mathrm{~cm}$ \\
\hline $\begin{array}{c}\text { Laser } \\
\text { Points }\end{array}$ & $10.61 \mathrm{~cm}$ & $11.92 \mathrm{~cm}$ & $10.78 \mathrm{~cm}$ \\
\hline
\end{tabular}

Table 4: The average distance between the land surveyor's points and the 3D model points

The averages shown in Table 4 present a value that is completely reachable in a day-to-day operational production of a topographic plan. The experimental value of the model precision is that of the control point placed at the center of the model. This point is perfectly identifiable in the model and in the field. Therefore, this implies that the point that was mapped in the model is the same as that mapped in the field, without ambiguity; the only error is due to pixel size. At that point an error of $1.0 \mathrm{~cm}$ was observed (knowing that the pixel

size is $0.50 \mathrm{~cm}$ and the pointer is $1.0 \mathrm{~cm}$ in diameter).

\section{COMPARISON WITH LAND SURVEYING CLASSICAL RESULTS}

Appendices A and B show the maps of UAV and classical surveying respectively.

Table 5 displays the main differences between the two techniques (classical and UAV). The values in the table represent what is estimated to be representative for that particular site.

\begin{tabular}{|c|c|c|}
\hline & Classical & $\begin{array}{c}\text { UAV } \\
\text { photogrammetry }\end{array}$ \\
\hline Duration in field & About $7 \mathrm{hr}$. & About $4 \mathrm{hr}$. \\
\hline Price & About $2,000 €$ & About $1,200 €$ \\
\hline Security & $\begin{array}{l}\text { Attributed to } \\
\text { construction } \\
\text { machinery }\end{array}$ & $\begin{array}{l}\text { Attributed to the } \\
\text { drone }\end{array}$ \\
\hline Precision & $\begin{array}{l}\text { Centimeters to } \\
\text { sub-centimeters }\end{array}$ & centimeters \\
\hline $\begin{array}{l}\text { Preprocessing } \\
\text { time }\end{array}$ & $\begin{array}{l}\text { Only logistic with } \\
\text { the client }\end{array}$ & $\begin{array}{l}\text { Legal procedures } \\
\text { with flight } \\
\text { authorities, } \\
\text { mayor's office } \\
\text { and logistic with } \\
\text { the client }\end{array}$ \\
\hline $\begin{array}{l}\text { Post-processing } \\
\text { time }\end{array}$ & About $6 \mathrm{hr}$. & About $6 \mathrm{hr}$. \\
\hline
\end{tabular}

Table 5: The differences between classical and UAV surveying

In terms of safety, the danger in operating a UAV comes from the UAV itself, but it is pretty moderate and can be easily avoided by any pilot with experience and who is conscious of the risk. Moreover, the operator is supposed to be in control of the risk, while in traditional topographic surveys the risk comes from elements that are out of the control of the land surveyor.

\section{DISCUSSION}

The potential capabilities in terms of precision are only restricted by the resolution of the image. Therefore, any level of precision could be reachable with the right type and number of ground control points. However, the problem associated with high image resolution is related to the computing power needed, since an increase in resolution means a major increase in the data volume.

However, it is not possible to say that UAVs can replace the work of land surveyors, since several problems appear with the use of a UAV. For instance, vegetation is the first obstacle that hinders generating a plan. The second obstacle is related to the complex and various process involved in working in urban areas with UAVs. The case study does not involve everything as it was not possible to fly over the neighbors' properties, which led to poor overlapping at the site borders (since flying was only permitted over the client's land). Indeed the aerial rules involve a lot of planning, administration and time-consuming tasks. This may lead to 
neglect or ignore mentioning the potential crashes. Finally, it is essential to have a very strong computing system to process and exploit the large amount of data required for generating a high-resolution model and plan.

Many possibilities can be explored in order to enhance the potential of UAVs. For example, the problem raised by vegetation obstacles can be overcome by taking pictures on the ground to complete the model (Tscharf et al., 2015) or using a more precise positioning system to avoid ground control points (Rehak and Skaloud, 2015). With regard to the administrative procedures, these should get lighter with more experience on both sides. Another hopeful evolution is the possibility of exporting the data on a cloud interface, where the project will be processed and data will be managed and exploited. Some solutions already exist and promise fully operational solutions allowing the images and ground control points to be exported while still working in the field by utilizing a $4 \mathrm{G}$ connection. This would enable a much faster process with an almost real-time mapping at centimeter level in the near future.

It is obvious that UAVs can't replace total stations (one can complement the other), therefore it is a good idea to use both together in order to develop extremely powerful mapping tools.

\section{CONCLUSION}

The main aim of this research was to determine whether UAVs can be operated at any type of site, particularly small ones (privately owned). To achieve that, two plans were created for the same site, one using traditional techniques and the other using UAVs. Afterwards the results of both were compared. The UAV plan was not complete enough to be fully exploitable because of the existence of a large amount of vegetation. But at the end, the results in terms of precision are acceptable, since the level of precision only depends on pixel size.

So in order to create more accurate models, the challenge seems to be more the amount of data needed to manage and the acquisition speed of ground control points. Indeed the level of precision reached can be achieved with a total station. However, this level cannot be reached using an RTK GNSS receiver. Actually, in certain conditions and with the latest developed technologies, a precision of about $1.0-2.0 \mathrm{~cm}$ (announced by the constructor) may be reachable. Utilizing a total station, the model can be created with more precision.

The error that resulted during GCP measurement is directly influences the quality of the model. Using GCP with lowquality RTK measures will actually alter the model. Moreover, the vegetation problem already identified also impacts the quality of the generated model. Really, without it, a good plan can be extracted and the parts that are well exposed can be vectorized seamlessly with high precision. However, the vegetation covered most of the important areas at the site of interest and made it impossible to issue a plan that could be deliverable.

These points show how the technique is promising; just some missing key innovations are required to be fully efficient for that kind of site. One of these innovations is developing intelligent landmarks that can interact with the drone. The other innovation that may lead to facilitating this type of measurement is normalizing the process for land surveyors and drone operators to work together. Such a process would allow the land surveyor to have easy access to safe flight and quality data. Actually, the land surveyor flying the drone will lead to depletion and loss of his time in planning the flight in considering several issues: weather conditions and administrative work, for instance, while the drone operator can plan all of these tasks while respecting the land surveyor's requirements in terms of resolution and overlap.

\section{ACKNOWLEDGEMENTS}

This work was made possible thanks to L'Imagerie Volante and Gexia Foncier géomètres experts and the support of the Ecole Spéciale des Travaux Publics-Paris.

\section{REFERENCES}

Arango, C. and Morales, C.A., 2015. Comparison Between Multicopter Uav and Total Station for Estimating Stockpile Volumes. The International Archives of Photogrammetry, Remote Sensing and Spatial Information Sciences, 40(1), p.131.

Barazzetti, L., Brumana, R., Oreni, D., Previtali, M. and Roncoroni, F., 2014. True-orthophoto generation from UAV images: Implementation of a combined photogrammetric and computer vision approach. ISPRS Annals of the Photogrammetry, Remote Sensing and Spatial Information Sciences, 2(5), p.57.

Barnes, G., Volkmann, W., Sherko, R., Kelm, K., World, T., $\&$ Washington, B. 2014. Drones for Peace : Part 1 of 2 Design and Testing of a UAV-based Cadastral Surveying and Mapping Methodology in Albania Paper prepared for presentation at the " 2014 WORLD BANK CONFERENCE ON LAND AND POVERTY " Copyright 2014 by Grenville Barnes, Walter V, 1-28

Bastonero, P., Donadio, E., Chiabrando, F. and Spanò, A., 2014. Fusion of 3D models derived from TLS and imagebased techniques for $\mathrm{CH}$ enhanced documentation. ISPRS Annals of the Photogrammetry, Remote Sensing and Spatial Information Sciences, 2(5), p.73.

Brutto, M.L., Garraffa, A. and Meli, P., 2014. UAV platforms for cultural heritage survey: first results. ISPRS Annals of the Photogrammetry, Remote Sensing and S

Colomina, P. Molina, Unmanned aerial systems for photogrammetry and remote sensing: A review, ISPRS Journal of Photogrammetry and Remote Sensing Volume 92, June 2014, Pages 79-97

Eling, C., Wieland, M., Hess, C., Klingbeil, L., and Kuhlmann, H.: DEVELOPMENT AND EVALUATION OF A UAV BASED MAPPING SYSTEM FOR REMOTE SENSING AND SURVEYING APPLICATIONS, Int. Arch. Photogramm. Remote Sens. Spatial Inf. Sci., XL-1/W4, 233239, doi:10.5194/isprsarchives-XL-1-W4-233-2015, 2015.

Fernández-Lozano, J. and Gutiérrez-Alonso, G., 2016. Improving archaeological prospection using localized UAVs assisted photogrammetry: An example from the Roman Gold District of the Eria River Valley (NW Spain). Journal of Archaeological Science: Reports, 5, pp.509-520.

Fraser, R. H., Olthof, I., Maloley, M., Fernandes, R., Prevost, C., and van der Sluijs, J.: UAV PHOTOGRAMMETRY FOR MAPPING AND MONITORING OF NORTHERN PERMAFROST LANDSCAPES, Int. Arch. Photogramm. Remote Sens. Spatial Inf. Sci., XL-1/W4, 361-361, doi:10.5194/isprsarchives-XL-1-W4-361-2015, 2015. 
Gonçalves, J.A. and Henriques, R., 2015. UAV photogrammetry for topographic monitoring of coastal areas. ISPRS Journal of Photogrammetry and Remote Sensing, 104, pp.101-111.

González-Aguilera, D., Fernández-Hernández, J., ManceraTaboada, J., Rodriguez-Gonzálvez, P., Hernández-López, D., Felipe-García, B., Gozalo-Sanz, I. and Arias-Perez, B., 2012. 3D modelling and accuracy assessment of Granite Quarry using unmanned aerial vehicle. ISPRS Ann. Photogram. Remote Sens. Spat. Inf. Sci, 1, pp.37-42.

Grenzdörffer, G.J., Engel, A. and Teichert, B., 2008. The photogrammetric potential of low-cost UAVs in forestry and agriculture. The International Archives of the Photogrammetry, Remote Sensing and Spatial Information Sciences, 31(B3), pp.1207-1214.

http://trl.trimble.com/docushare/dsweb/Get/Document 262358/022543-155J_TrimbleM3_DS_0414_LR.pdf

Jin, W., Ge, H.L., Du, H.Q. and Xu, X.J., 2009. A Review on Unmanned Aerial Vehicle Remote Sensing and Its Application [J]. Remote Sensing Information, 1, pp.88-92.

JONES IV, G.P., Pearlstine, L.G. and Percival, H.F., 2006. An assessment of small unmanned aerial vehicles for wildlife research. Wildlife Society Bulletin,34(3), pp.750-758.

Kavanagh B.F. and Glenn Bird S.J., 1996. Surveying principles and applications, 4th ed., Prentice Hall, pp. 257-264

Kim, D.I., Song, Y.S., Kim, G. and Kim, C.W., 2014. A study on the application of UAV for Korean land monitoring. Journal of the Korean Society of Surveying, Geodesy, Photogrammetry and Cartography, 32(1), pp.29-38.

Kulur, S., Yildiz, F., Selcuk, O., and Yildiz, M. A.: THE EFFECT OF PIXEL SIZE ON THE ACCURACY OF ORTHOPHOTO PRODUCTION, ISPRS Ann. Photogramm. Remote Sens. Spatial Inf. Sci., III-4, 53-57, doi:10.5194/isprsannals-III-4-53-2016, 2016.

Küng, O., Strecha, C., Beyeler, A., Zufferey, J.C., Floreano, D., Fua, P. and Gervaix, F., 2011. The accuracy of automatic photogrammetric techniques on ultra-light UAV imagery. In UAV-g 2011-Unmanned Aerial Vehicle in Geomatics (No. EPFL-CONF-168806).

Kurczynski, Z., Bakuła, K., Karabin, M., Kowalczyk, M., Markiewicz, J. S., Ostrowski, W., Podlasiak, P., and Zawieska, D.: THE POSSIBILITY OF USING IMAGES OBTAINED FROM THE UAS IN CADASTRAL WORKS, Int. Arch. Photogramm. Remote Sens. Spatial Inf. Sci., XLI-B1, 909915, doi:10.5194/isprs-archives-XLI-B1-909-2016, 2016.

Müller, H.: BRIDGING THE GAP BETWEEN SURVEYORS AND THE GEO-SPATIAL SOCIETY, Int. Arch. Photogramm. Remote Sens. Spatial Inf. Sci., XLI-B4, 683-686, doi:10.5194/isprs-archives-XLI-B4-683-2016, 2016.

Rehak, M. and Skaloud, J., 2015. Fixed-wing micro aerial vehicle for accurate corridor mapping. ISPRS Annals of the Photogrammetry, Remote Sensing and Spatial Information Sciences, 2(1), p.23.

Remondino, F., Barazzetti, L., Nex, F., Scaioni, M. and Sarazzi, D., 2011. UAV photogrammetry for mapping and 3d modeling-current status and future perspectives. International Archives of the Photogrammetry, Remote Sensing and Spatial Information Sciences, 38(1), p.C22.

Rui-sheng, M.A., Han, S.U.N., Lun-ji, M.A., Zong-gui, L.I.N. and Chao-hui, W.U., 2006. Land-use Survey Based on Image from Miniature Unmanned Aerial Vehicle [J]. Remote Sensing Information, 1, p.012.

Stöcker, C., Eltner, A. and Karrasch, P., 2015. Measuring gullies by synergetic application of UAV and close range photogrammetry - A case study from Andalusia, Spain. Catena, 132, pp.1-11.

Tscharf, A., Rumpler, M., Fraundorfer, F., Mayer, G. and Bischof, H., 2015. On the Use of Uavs in Mining and Archaeology-Geo-Accurate 3d Reconstructions Using Various Platforms and Terrestrial Views. ISPRS Annals of the Photogrammetry, Remote Sensing and Spatial Information Sciences, 2(1), p.15.

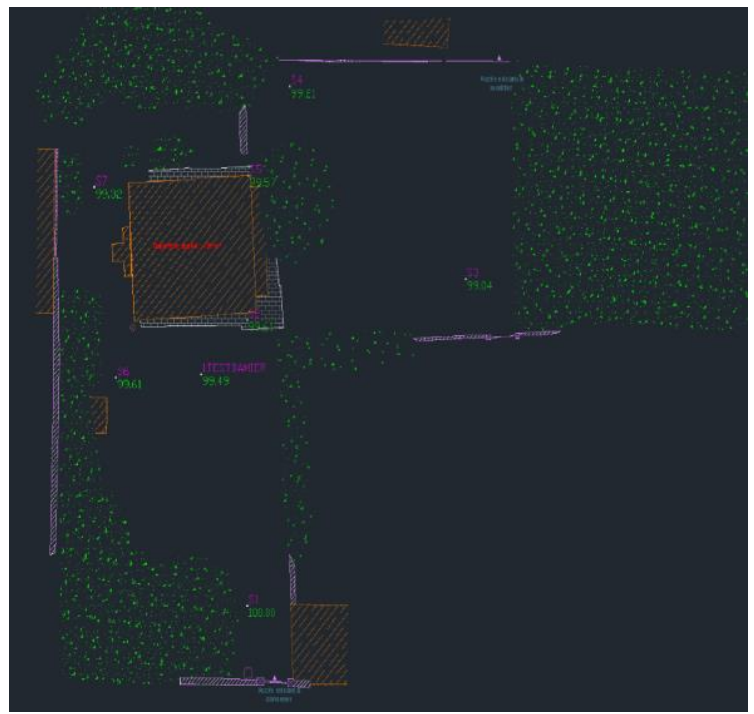

Appendix A: UAV map

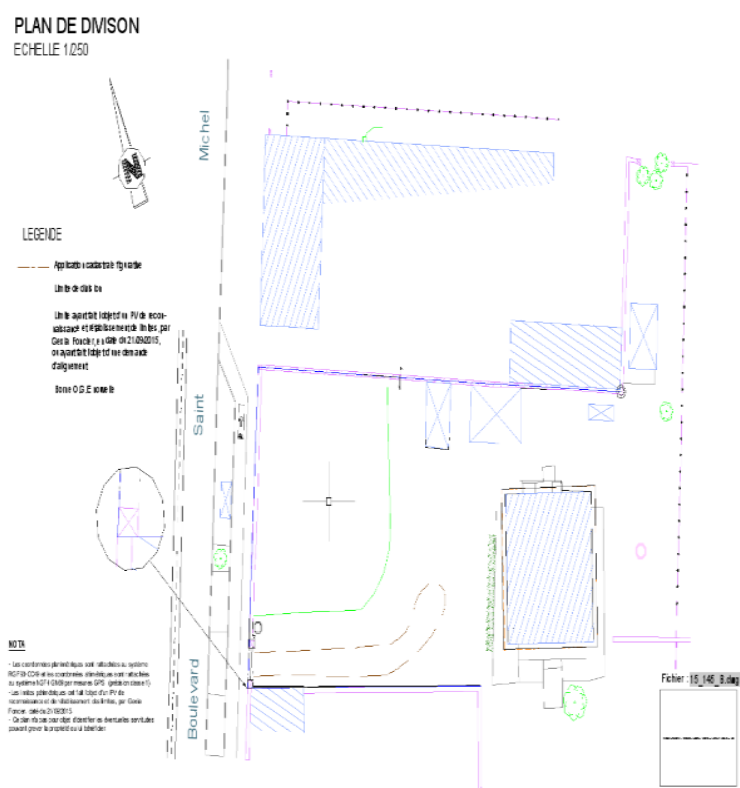

Appendix B: Classical surveying map 